\title{
Design para a transformação da sociedade: um olhar crítico para o discurso dos movimentos Do It Yourself, Open Design e Makers no contexto contemporâneo
}

Design for social change: a critical view of the Do It Yourself, Open
Design, and Makers movements in the contemporary context

MARQUES, Pamela

Universidade de Brasília - UnB I marques.pan@gmail.com

GARROSSINI, Daniela Favaro

Universidade de Brasília - UnB I daniela.garrossini@gmail.com

\begin{abstract}
Resumo
Este trabalho analisa a tendência recente de emergência de movimentos de Design com discurso idealista, que, em resposta a insuficiências identificadas no modelo econômico atual, acreditam que a massificação do acesso a tecnologias de fabricação tem o potencial de democratizar a autonomia produtiva - e assim catalisar a emancipação social. Considera-se expoentes desta corrente, por sua popularidade, os movimentos Do It Yourself, Open Design e Makers. Para entender estes grupos e como se inserem na dinâmica do sistema global, examina-se, através de revisão bibliográfica, a afinidade de seu discurso com o capitalismo contemporâneo e sua ideologia legitimadora; e propõe-se uma reflexão sobre como suas narrativas e propostas interagem com as atuais relações de produção.
\end{abstract}

Palavras Chave: Capitalismo contemporâneo. Autonomia produtiva. Transformação social.

\section{Abstract}

This paper analyses the recent trend of emerging Design movements - with an idealistic discourse - which, in response to shortcomings in the current economic model, believe expanding the access to manufacturing technologies has the potential to democratize the productive autonomy, thereby catalyzing social emancipation. For their popularity, movements such as Do It Yourself, Open Design and Maker Culture are considered flagship examples of that trend. In order to understand those groups and how they integrate into the dynamics of the global system, we examine the affinity between their discourse and the legitimating ideology of contemporary capitalism through a literature review - thus presenting a reflection on how their narratives and propositions interact with current production relationships.

Keywords: Contemporary capitalism. Productive autonomy. Social change. 


\section{MOVIMENTOS EMERGENTES NO DESIGN}

Nos últimos anos, tem sido notável o surgimento, no âmbito do Design, de movimentos advogando a adoção de posturas e conjuntos de ações com o objetivo de solucionar problemas oriundos do modelo econômico atual. São iniciativas focadas em fomentar a criatividade proporcionando a massificação do acesso a ferramentas projetuais e tecnologia de manufatura. Alguns exemplos relevantes são o Do It Yourself, o Open Design e, particularmente, o movimento Maker no Brasil - que chega a advogar "uma nova revolução industrial através da democratização da inovação" (MAKERS, 2017b).

Considerado precursor do incentivo à criatividade e à autonomia produtiva, o Do It Yourself (D.I.Y), em português "faça você mesmo", se caracteriza fundamentalmente como um método de produção, reconstrução e/ou conserto manual de objetos do cotidiano a partir de materiais de fácil acesso. Com a forte popularização, o termo passou a abranger também outras habilidades além da confecção de utensílios, como a produção de música independente. E se já era popular antes da era digital, com a internet a prática ganhou outra dimensão: nas redes sociais, são inúmeros os vídeos ensinando o passo a passo para a confecção dos mais variados tipos de artefatos. A propagação dos tutoriais nestas redes também potencializa a melhora incremental das técnicas que retratam, conforme as pessoas interagem e publicam suas próprias críticas e tutoriais em reação às publicações de outros.

Segundo Nunes (2010), a razão desta prática está alinhada com o pensamento de Ellen Lupton - de que a motivação está na satisfação das pessoas em transformar suas ideias em objetos reais e, em seguida, poder compartilhar suas criações com os outros - acrescido de outras razões como a falta de acesso a determinados recursos e materiais que impossibilita parte da população mundial de participar da sociedade do consumo (NUNES, 2010, p. 45).

Outro movimento é o Open Design, frequentemente associado com a comunidade de software livre, na qual autores de programas de computador divulgam seu código-fonte para que outras pessoas possam executar, replicar, redistribuir e modificar de acordo com suas necessidades, melhorando-o e 
adaptando-o constantemente. O sistema operacional Linux ${ }^{1}$ e o navegador Firefox ${ }^{2}$, são alguns exemplos notáveis de programas abertos.

O Open Design é a aplicação dessa lógica à prática do Design; soluções projetuais são disponibilizadas por seus criadores para produção, aprimoramento e compartilhamento. Mas ele tem ambições mais amplas e se propõe a projetar serviços, produtos, sistemas e até sociedades abertas e flexíveis, isto é, livres para utilização, adaptação e compartilhamento. Um movimento global que atua localmente, de forma colaborativa, tanto física quanto virtualmente.

De acordo com Cabeza, Moura e Rossi (2014), é a promoção de uma "cultura livre" e pode ser considerado "uma filosofia projetiva do ambiente humano, que por meio da inovação social, oferece soluções diferentes, autogestadas, que nem o Estado nem os modelos lineares oferecem" (CABEZA; MOURA; ROSSI, 2014, p. 60). Neste sentido, é possível compreender que, com o avanço das tecnologias de comunicação e informação, ampliou-se o discurso do aumento e fortalecimento do trabalho em rede que viabiliza projetar soluções para problemas de ordem social transformando o espaço urbano. $\mathrm{Na}$ perspectiva do Open Design, este processo deve envolver a comunidade local, com os designers atuando como mediadores e a tecnologia exercendo um papel fundamental na otimização dos resultados. Por fim, se caracteriza também como uma tentativa de maior independência do mercado.

Outro exemplo, bastante proeminente nos últimos anos, é o movimento Maker, que assim como o Open Design, é um movimento global que possui características próprias de acordo com os diversos ambientes em que atua. No Brasil, os chamados "fazedores" produzem desde artesanato tradicional até a alta tecnologia eletrônica. Mas são reconhecidos justamente pelo uso de ferramentas digitais, utilizando máquinas de fabricação pessoal e, assim como os adeptos do D.I.Y., compartilhando seus feitos pela internet.

Um ponto comum de articulação dos Makers e dos adeptos do Open Design são os Fab Labs - uma rede global de laboratórios de fabricação digital onde é possível prototipar de forma rápida e colaborativa os mais variados objetos, usando máquinas como impressoras 3D, cortadoras a laser, faca ou jato d'água, fresadoras CNC, etc. Para Eychenne e Neves (2013), esses espaços

1 Sistema operacional criado pelo programador finlandês Linus Torvald considerado o exemplo mais relevante de software livre e de código aberto, usado como base para o desenvolvimento de outros softwares livres ou com fins comerciais. (LINUX, 2017).

2 Navegador livre e multiplataforma desenvolvido pela Fundação Mozilla. Há controvérsias quanto à sua classificação como software livre apesar de seguir essencialmente a filosofia da comunidade e possuir código aberto. Por haver restrições que conflituam com as liberdades fundamentais do usuário estabelecidas pela comunidade, pode ser definido como partidário do movimento de Código Aberto ou Open Source - iniciativa comunitária de desenvolvimento de softwares de códigos abertos com interesses mercadológicos. (MOZILLA, 2017). 
não são destinados apenas a empreendedores, designers e artistas, são abertos a todos, sem distinção de experiência, diploma, projeto ou uso, tornando-os espaços férteis para a inovação social (EYCHENNE; NEVES, 2013, p. 9-10).

Este tipo de prática vem influenciando inclusive o poder público, como no caso do Fab Lab Livre SP (FAB LAB LIVRE SP, 2017) da prefeitura de São Paulo. Esta iniciativa deu origem a uma rede de 12 laboratórios públicos com ferramentas de fabricação digital, marcenaria e mecânica, computadores com software de desenho digital e equipamentos de eletrônica e robótica, além de ofertas de oficinas, cursos e palestras. Segundo o site da rede, buscam disseminar a produção do conhecimento em tecnologia, ciência, arte e inovação, democratizar o acesso a tecnologias e vivência, com o objetivo "fomentar o desenvolvimento de ideias criativas e inovadoras que beneficiam a comunidade e o surgimento de novas oportunidades profissionais" (FAB LAB LIVRE SP, 2017).

Outro exemplo da abrangência do movimento é o projeto de residência Favelado 2.0 - Construindo Gambiarras para o Futuro, iniciativa do GatoMídia³. A residência ocorreu durante duas semanas, no começo de 2016, e debateu temas como criatividade, inovação, movimento Maker, gambiarra. Desdobrouse no documentário "Quem são os makers da favela?" que busca questionar porque a sociedade continua a debater todos esses temas sem valorizar a origem das soluções criativas e espontâneas: a massa popular.

A partir desse cenário, é possível apontar pelo menos dois fatores presentes nesses movimentos. O primeiro, uma preocupação com o futuro da sociedade sob o atual modelo econômico, numa expressão do consenso cada vez maior, no debate público, sobre a necessidade de se colocar seriamente em pauta a questão da responsabilidade social. O segundo, especialmente no Open Design e no movimento Maker, é o discurso entusiasmado e um tanto idealista que mantêm ou com que são descritos, com ênfase no potencial socialmente disruptivo e transformador, ou mesmo "revolucionário", da massificação do acesso a métodos e ferramentas associados à prática do Design.

Papanek (1984), já na década de 70, alertava para a necessidade de que os designers se conscientizem do potencial impacto de sua atuação na cadeia produtiva e na sociedade, e passem a incluir esta consideração no conjunto de critérios comuns de mercado que regem seu método de trabalho. Naquela época, estas ideias pioneiras Ihe renderam escárnio e ostracismo acadêmico (PAPANEK, 1984).

Bonsiepe (2011) também fala sobre a responsabilidade do profissional da área em transcender a postura crítica e passar à intervenção com atos 
projetuais; concretizar sua predisposição de mudar o que for necessário na realidade, mas sem se distanciar dela. Ele espera

[...] formar uma consciência crítica frente ao enorme desequilíbrio entre os centros de poder e os que são submetidos a eles. A partir dessa consciência, podem-se explorar espaços alternativos, não se concentrando com a petrificação das relações sociais. Esse desequilíbrio é profundamente antidemocrático, uma vez que nega a participação em um espaço autônomo de decisão. Trata os seres humanos como meros consumidores no processo de coisificação (BONSIEPE, 2011, p. 21).

Hoje esses discursos são amplamente aceitos na comunidade internacional e mesmo no senso comum - o que é significativo da evolução da percepção pública a respeito do tema e da consolidação da visão de mundo que informa a narrativa dos "movimentos de Design" já mencionados. Contudo, o ativismo de tais movimentos em prol da mudança social parece não ser precedido de uma leitura realista da complexidade de forças afetando o contexto em que atuam, o que imprime um caráter utópico ao seu discurso.

Cabeza, Moura e Rossi (2014), por exemplo, em artigo analisando o conceito de Open Design, referem-se a essa prática como o caminho para a libertação de um modo de produção individualista e monopolizador para outro baseado no trabalho livre, colaborativo e cooperativo (CABEZA; MOURA; ROSSI, 2014).

\footnotetext{
O Open Design é a recuperação da capacidade do homem, ou melhor, das comunidades, para adaptar e transformar seu ambiente natural, que estava monopolizado por um modo de produção fechado, individualista, egoísta e monopolizador. O Open Design é agora a emancipação para um modo de produção comunitário, libertador, transparente, aberto, baseado no trabalho livre, colaborativo e cooperativo. (CABEZA; MOURA; ROSSI, 2014, p .65)
}

No entanto, não descreve como as relações de poder estabelecidas no sistema capitalista seriam erradicadas para o fim pretendido.

O mesmo ocorre quando Cavallini, fundador da Makers - "plataforma de educação e inovação focada na prototipagem e desenvolvimento de produtos para a nova Revolução Industrial" (MAKERS, 2017a) - descreve o movimento Maker no site da empresa. Ele afirma que pessoas e pequenas empresas não estão mais limitadas à produção em pequena escala e à distribuição local (MAKERS, 2017a). 
Qualquer pessoa pode criar, prototipar, produzir, vender e distribuir qualquer produto [...]

Até então, acreditávamos que este era o tipo de tarefa viável apenas para grandes indústrias e corporações. Mas o mundo mudou... e continua mudando.

[...] A informação é abundante. O conhecimento (formal e informal) está cada vez mais acessível na internet. Não dependemos mais das fontes tradicionais de investimento e a tecnologia está cada vez mais barata e acessível, inclusive nos trazendo soluções [...] que tornam ainda mais acessíveis (mais fácil, mais barato e mais rápido) criar produtos e serviços.

É uma nova revolução industrial através da democratização da inovação.

[...] pessoas, startups e pequenas empresas não estão mais limitados à produção em pequena escala e de distribuição local (MAKERS, 2017a).

Assim como no blog Fazedores (2017), mantido pelo engenheiro da computação Manoel Lemos com o objetivo de fomentar e divulgar o movimento Maker, ele é descrito como

[...] um movimento super forte e relevante que tem cara de revolução e que está mudando totalmente a forma com que criamos e nos relacionamos com as coisas. O empreendedorismo é super forte e presente no Movimento Maker já que cada vez mais vemos fazedores criando novas empresas que nasceram de seus projetos pessoais (FAZEDORES, 2017).

A despeito da veemência com que se afirma o caráter revolucionário destes movimentos, eles também parecem apresentar pontos de contato com práticas típicas da configuração do capitalismo contemporâneo e com a narrativa legitimadora que o acompanha. Esta interseção permite esboçar possíveis limites para seu impacto transformador, ou até mesmo, constatar que no atual cenário socioeconômico se tornam apenas peças a serviço do sistema vigente.

\section{CAPITALISMO CONTEMPORÂNEO}

Este é o panorama do atual modo de produção no qual surgem os movimentos emergentes de Design, e a matriz ideológica na qual se funda seu discurso: 
A segunda metade do século $X X$ viu a gradual transição das formas tradicionais de organização do capitalismo industrial para modelos como o pósfordismo e toyotismo. O foco deixava de ser a produção em massa rigidamente padronizada e se voltava para a flexibilidade, buscando atender com mais eficiência a particularidades na demanda de públicos específicos e responder mais prontamente a transformações dos hábitos de consumo.

Em meio a esse processo o mundo passou pelo desenvolvimento vertiginoso das tecnologias de transporte e comunicação, mudanças que impulsionaram a globalização. Esse fenômeno catalisou uma integração cultural mundial pela facilidade de acesso à informação, particularmente com o advento e popularização da internet; e deu causa, também, à pulverização e internacionalização da atuação capitalista, conforme as empresas se tornavam transnacionais na busca por condições mais favoráveis de acumulação e exploração, como mão de obra barata, impostos mais baixos e maiores facilidades locais.

Cabe apontar, conforme Milton Santos (2006), que a globalização não acontece de forma homogênea. Ela se restringe àqueles que possuem capital para adquirir ou desenvolver inovações tecnológicas, sobretudo no campo da informação; e que a distribuição em massa da informação é um produto das grandes corporações que detém o poder e a manipulam de acordo com a lógica do capital (SANTOS, 2006).

Este contexto resultou numa configuração para o capitalismo contemporâneo que Yann Moulier Boutang (2011) chamou de capitalismo cognitivo.

[...] que é fundado na acumulação de capital imaterial, na disseminação de conhecimento e no papel central da economia do conhecimento. Esta forma se adapta paradoxalmente ao mundo da competição exacerbada do capitalismo Pós-Fordista e industrial (MOULIER BOUTANG, 2011, p. 50, tradução nossa).

O autor descreve o sistema como um modo de acumulação cujo objeto é principalmente o conhecimento, que se torna a principal fonte de valor e foco do processo de valorização. Direitos de propriedade, posicionamento em redes, alianças e gerenciamento de projetos tornam-se cruciais. As estratégias organizacionais neste capitalismo se orientam para a busca de um posicionamento que potencialize a capacidade de se engajar em processos criativos e capturar seus benefícios (MOULIER BOUTANG, 2011).

Larsen (2014) acrescenta que, na atual divisão de trabalho, tornouse "obrigação" na parte mais rica do Ocidente produzir e vender conceitos, programas e sistemas de governança para sobreviver e lidar eficientemente com 
a globalização. Conhecimento, conceitos, originalidade, viram força estratégica de produção e mercadorias importantes.

No capitalismo atual, cada vez menos pessoas trabalham na produção material [...] enquanto cada vez mais pessoas entregam produtos imateriais (produtos da economia da experiência e atenção, designs, dispositivos de conhecimento). Visto por seus próprios olhos, o capitalismo do amanhã é limpo, inteligente e esperto. A produção poluente e os trabalhos "sujos" são exportados para outras regiões onde a força de trabalho é mais barata (LARSEN, 2014, p. 161, tradução nossa).

Assim, a sociedade passa a consistir de uma proporção crescente de trabalhadores de conhecimento, que têm de investir enormes quantidades de energia em sua marca pessoal. Aprendizado vitalício se torna chave, e ser criativo se torna obrigação para todos, independente de formações ou atuações profissionais específicas.

Em termos ideológicos, Boltanski e Chiapello (2009) analisam como as mudanças das condições materiais e sociais afetaram a narrativa legitimadora do capitalismo. Em resposta aos novos modos de vida surgidos nas últimas décadas e ao "sucesso público" (BOLTANSKI; CHIAPELLO, 2009, p. 454) das críticas ao mundo regido pelo capital, a rearticulação retórica do modo de produção a este novo contexto deu origem ao que chamaram de "terceiro espírito do capitalismo" (BOLTANSKI; CHIAPELLO, 2009).

Casaqui (2016), analisando a expressão do conceito de Boltanski e Chiapello no empreendedorismo, resume este terceiro espírito:

[...] a mítica em torno do empreendedor é promovida como a redenção ante as históricas mazelas do mundo do trabalho, ante as dissonâncias com o espírito libertário juvenil que ganhou força no contexto da contracultura da década de 1960, ante a separação entre trabalho e lazer, entre atividade laboral e felicidade.

Como contraponto a esse cenário anterior, emerge a imagem contemporânea do homem conexionista, adaptado ao trabalho em redes e à flexibilização das relações laborais, identificado com a indústria criativa, com o espírito empreendedor, com a cultura globalizada, com as tecnologias digitais [...] (CASAQUI, 2016).

Acrescenta que, ainda de acordo com Boltanski e Chiapello, tal sujeito possui como atributo principal o uso estratégico das relações, manipulando comportamentos como empatia e afeto para outros contextos em que os atos 
de colaboração e solidariedade possam resultar em vantagens financeiras. Em síntese, "o cenário em torno do homem conexionista é o da mercantilização das relações [...]" (CASAQUI, 2016).

É possível notar que os movimentos analisados são, em certa medida, pautados nesses termos. Um exemplo é a missão da plataforma Makers (2018) como promotora do movimento no Brasil, que é descrita, no site da empresa, como "dar mais poder para os talentos brasileiros" (MAKERS, 2018). Não importando se este talento é um dentista, psicólogo, designer, engenheiro, criança, adulto, homem ou mulher. Uma verdadeira vocação para despertar o potencial criativo do cidadão comum, por meio do oferecimento de serviços mesmo que o lucro seja descrito como apenas um dos resíduos positivos do trabalho desenvolvido. Uma expressão bastante precisa das características do homem conexionista.

\section{A INSERC̣ÃO DA NARRATIVA DOS MOVIMENTOS DE DESIGN NO CONTEXTO ATUAL}

As semelhanças entre o discurso capitalista contemporâneo e o jargão dos movimentos de Design sugere uma proximidade das duas narrativas. Essa conexão pode ser mera expressão da origem de ambas no mesmo contexto cultural e produtivo.

No entanto, se o grau desta interseção de valores e modos de pensar implicar em uma afinidade, mesmo inconsciente, de objetivos, tais movimentos poderiam estar desempenhando um inadvertido papel de reforço das relações de produção que questionam - em mais um exemplo da capacidade do capitalismo de se rearticular e assimilar a oposição a si.

Casaqui (2016), por exemplo, ao analisar o discurso do empreendedorismo, chama a atenção para o esvaziamento dos conceitos de transformação social e revolução. "A inovação disruptiva abarca a ideia de revolução, restringindo-a à prática empreendedora, ao mercado como entidade totalizante, que tudo comporta" (CASAQUI, 2016). Estes conceitos são ressignificados e instrumentalizados como peças retóricas a serviço da legitimação do capitalismo.

Eis que encontramos, de forma nítida, o paradoxo apontado por Boltanski e Chiapello (2009) sobre o mundo conexionista e sua forma de mercantilizar as relações. A solução de problemas graves do planeta, pela formação discursiva, é praticamente um efeito colateral, uma consequência quase improvável do sucesso do empreendimento. O empreendedor se coloca no lugar de 
liderança, mas seu projeto de transformação da sociedade é, antes de tudo, um projeto de negócios, que mobiliza o sentido da mudança para encontrar seu lugar no mercado competitivo e predatório (CASAQUI, 2016).

Um raciocínio semelhante ao da narrativa dos movimentos emergentes de Design, segundo a qual a potencialização da entrada de novos atores na arena capitalista será suficiente para gerar efeitos como uma "nova Revolução Industrial" e mudar a relação da humanidade com o modo de produção.

A partir do pensamento de Haiven (2012) é possível apontar ainda alguns pontos cegos do discurso salvacionista no qual a criatividade e inovação são tratadas como panaceias que vão revolucionar o mundo. O capitalismo muda drasticamente os tipos de criatividade que valorizamos e orienta o esforço criativo humano para o que é lucrativo para poucos. A mudança sistêmica não é inerente à massificação da economia criativa ${ }^{4}$, e se ela estiver a serviço dos mesmos objetivos, obterá os mesmos resultados. No contexto atual, o conjunto do que consideramos criatividade se torna cada vez mais amplo. Mas se isso potencializa a criação de novas formas de comunidade e de espaços de decisões, também continua ocorrendo como parte do aumento da pobreza global, da exploração e do caos social (HAIVEN, 2012).

"A despeito disso, professores e ideólogos do establishment declararam que a nossa é uma era de "capitalismo criativo". Capitalismo, eles argumentam, é o melhor sistema por prover oportunidades criativas para todos" (HAIVEN, 2012, tradução nossa).

Para muitas pessoas - principalmente empreendedores - o capitalismo prospera na dinâmica conhecida como "destruição criativa", uma competição que força empresas constantemente a se reinventar para não morrer ou serem mortas por concorrentes. Acredita-se que essa busca permanente por lucro causa inovação e dinamismo.

O custo invisível de toda essa "criatividade" são os tremendos efeitos no ambiente humano e natural conforme corporações competem para encontrar novos meios de cortar custos (eliminar/degradar empregos) ou "externalizá-los" por meio de subcontratação, globalização ou forçando governos a pagar por seus malfeitos. Sem contar as enormes revoltas sociais quando uma firma fecha suas

4 Termo utilizado de acordo com a definição proposta pelo Plano da Secretaria da Economia Criativa - Políticas, diretrizes e ações 2011 a 2014 do Ministério da Cultura - MINC: "definimos Economia Criativa partindo das dinâmicas culturais, sociais e econômicas construídas a partir do ciclo de criação, produção, distribuição/circulação/difusão e consumo/ fruição de bens e serviços oriundos dos setores criativos, caracterizados pela prevalência de sua dimensão simbólica. (BRASIL, 2012, p. 23). 
portas ou se muda porque não foi "criativa" o suficiente, ou os custos ecológicos de inúmeras corporações competindo para "criar" milhares de marcas de produtos quase idênticos (HAIVEN, 2012, tradução nossa).

Haiven (2012) nota também que as disputas sob o capitalismo cognitivo continuam as mesmas. Pessoas trabalham juntas por maior controle sobre suas condições de trabalho; criam novas comunidades e modos de vida que tentam operar fora da dinâmica capitalista; rejeitam a forma como o sistema hierarquiza a sociedade; tentam proteger seus governos da ganância capitalista, e às vezes conseguem transformar completamente sua economia e sociedade (HAIVEN, 2012).

Apesar de novos aspectos, a luta contra o sistema continua a mesma de fases anteriores; mas o individualismo competitivo estimulado pelo capitalismo criativo, aliado à insegurança material que ele gera, contribui para a formação de uma mentalidade que desampara os trabalhadores na busca dos seus próprios interesses. Quando se vêem como agentes criativos livres e indivíduos econômicos com poder de decisão, em vez de uma coletividade explorada, a organização coletiva de classe fica difícil; conforme pulam de emprego em emprego ou de contrato em contrato para ganhar o sustento, sobra pouco espaço para a organização de coletividades permanentes e o desenvolvimento de um hábito de compartilhamento que estimule a solidariedade.

Do ponto de vista material, Harvey (1993), analisando as transformações da economia capitalista a partir da década de 70, descreve um quadro pouco animador para as perspectivas revolucionárias da democratização produtiva: “O incremento da capacidade de dispersão geográfica de produção em pequena escala e de busca de mercados de perfil específico não levou necessariamente [...] à diminuição do poder corporativo" (HARVEY, 1993, p. 149-150). Num mundo em que a informação, o conhecimento e a capacidade de tomar decisões rápidas se tornaram cruciais, a grande corporação compete com vantagens sobre pequenos negócios. A despeito das mudanças do pós-fordismo terem aumentado o número de pequenos negócios, elas também levaram a uma maior consolidação das grandes corporações (HARVEY, 1993).

\section{CONSIDERAC̣ÕES FINAIS}

Neste quadro, o surgimento de movimentos como os analisados neste trabalho, capazes de identificar defeitos no sistema e buscar resolvêlos, é bem-vindo e louvável. O Design, como abordagem de solução de problemas com potencial de catalisar inovação social, tem capacidade - e mesmo a responsabilidade - de ajudar e até protagonizar este esforço. Mas as condições descritas sobre o modo de regulação e legitimação do capitalismo 
- o conhecimento como fonte principal de valor, a precarização do trabalho, a obrigação de ser "criativo", a mercantilização das relações; a capacidade de assimilar as críticas e ameaças e se rearticular em reação a elas, comoditizando até mesmo a retórica anticapitalista enquanto mantém intactas suas dinâmicas de poder e relações de produção - indicam obstáculos que podem tolher este potencial.

Somado a isso, a insuficiência e instabilidade do sistema econômico atual e seus impactos globais são questões que precisam ser abordadas pela sociedade, e vêm sendo discutidas seriamente por um número crescente de pessoas. Considera-se, então, a mudança para um modo de vida mais sustentável e inclusivo uma necessidade.

No entanto, se tais movimentos perdem de vista os aspectos centrais do modo de produção, cujos defeitos querem solucionar, a pretendida "revolução" é roubada de seu impacto transformador, e se torna apenas mais um foco de adaptação e reforço desse sistema. A mera democratização de ferramentas produtivas e a consequente entrada de novos atores em um capitalismo já consolidado podem ter um efeito bastante limitado na maneira como sua dinâmica ocorre - principalmente para os ambiciosos fins declarados.

O fundamento do Design - independente de vertentes e visões - tem como condição a análise complexa e sistêmica do problema a ser resolvido, abarcando não só a perspectiva do objeto, mas também o processo do entorno, para que realmente atenda ao objetivo proposto. Os apontamentos levantados neste trabalho sugerem que os movimentos de Design estudados parecem partir de uma visão acrítica do sistema econômico em que estão inseridos. Seus discursos, na verdade, convergem com a narrativa legitimadora em construção para o capitalismo contemporâneo, acirrando condições desiguais.

É imprescindível, portanto, que estes movimentos ampliem sua percepção de como funciona o contexto socioeconômico sobre o qual querem atuar, e como suas iniciativas se integram neste quadro. Este é o primeiro passo necessário para compreender o problema em sua totalidade e fundamentar um processo de Design realmente revolucionário, capaz de proporcionar uma transformação social estrutural. 


\section{REFERÊNCIAS}

BOLTANSKI, Luc; CHIAPELLO, Ève. O novo espírito do capitalismo. São Paulo: M. Fontes, 2009.

BONSIEPE, Gui. Design, cultura e sociedade. São Paulo: Blucher, 2011.

BRASIL. Ministério da Cultura. Plano da Secretaria da Economia Criativa: políticas, diretrizes e ações, 2011 - 2014. Brasília, 2012.

CABEZA, Edison Uriel Rodríguez; MOURA, Mônica; ROSSI, Dorival. Design aberto: prática projetual para a transformação social. Strategic Design Research Journal, São Leopoldo, v. 7, n. 2, p. 56-64, maio/ago. 2014. Disponível em: <http://revistas.unisinos.br/index.php/sdrj/article/viewFile/ sdrj.2014.72.02/4619>. Acesso em: 9 maio 2018.

CASAQUI, Vander. Esboços e projetos da sociedade empreendedora: mundo conexionista, sociabilidade e consumo. Famecos, Porto Alegre, v. 23, n. 3, 2016.

EYCHENNE, Fabien; NEVES, Heloisa. Fab Lab: a vanguarda da nova revolução industrial. São Paulo: Fab Lab, 2013.

FAB LAB LIVRE SP. O que é. Disponível em: <fablablivresp.art.br/o-que-e>. Acesso em: 5 out. 2017.

FAZEDORES. Sobre. Disponível em: <blog.fazedores.com/sobre/>. Acesso em: 5 out. 2017.

GATOMÍDIA. Blog. Disponível em: <gatomidia.wordpress.com>. Acesso em: 5 out. 2017.

HAIVEN, Max. Privatizing creativity. 2012. Disponível em: <artthreat.net/ 2012/10/ privatizing-creativity/>. Acesso em: 10 out. 2017.

HARVEY, David. A condição pós-moderna. São Paulo: Loyola, 1993.

LARSEN, Steen Nepper. Compulsory creativity. Culture Unbound, Linköping, v. 6, p. 159-178, 2014.

LINUX. About the Linux Foundation. Disponível em: <https://www. linuxfoundation.org/about/>. Acesso em: 28 nov. 2017.

MAKERS. Nossa missão. Disponível em: <http://makers.net.br/sobre/nossamissao/>. Acesso em: 5 abr. 2018.

MAKERS. Quem somos. Disponível em: <http://makers.net.br/sobre/quemsomos/>. Acesso em: 5 out. 2017a.

MAKERS. Sobre. Disponível em: <makers.net.br/sobre/>. Acesso em: 9 out. 2017b.

MOULIER BOUTANG, Yann. Cognitive capitalism. Cambridge: Polity Press, 2011. 
MOZILLA. Addendum ao manifesto Mozilla: compromisso por uma internet saudável. Disponível em: <https://www.mozilla.org/pt-BR/about/ manifesto/>. Acesso em: 5 nov. 2017.

NUNES, Rui Filipe Vieira da Cruz. Uma nova estratégia de design de produto virada para o "Faça você mesmo": fundamentos, aplicabilidade e consequências num futuro social sustentável. 2010. Dissertação (Mestrado em Design de Produto) - Faculdade de Arquitectura - Universidade Técnica de Lisboa, Lisboa, 2010.

PAPANEK, Victor Joseph. Design for the real world. New York: Van Nostrand Reinhold, 1984.

SANTOS, Milton. A natureza do espaço: técnica e tempo, razão e emoção. São Paulo: Universidade de São Paulo, 2006. 